\title{
INSTRUMENTOS FINANCIEROS COMPATIBLES CON LA SHARÍA: ¿UNA ALTERNATIVA ÉTICA A LA FINANCIACIÓN CONVENCIONAL?
}

Bruno Martín Baumeister Recibido: Diciembre 12 de 2014 Aprobado: Marzo 15 de 2015

\section{RESUMEN}

El peso demográfico de la población musulmana en el mundo, unido al crecimiento económico de algunos países del Golfo Pérsico ha contribuido a que el derecho financiero islámico represente en la actualidad una práctica jurídica cada vez más implantada en países de África, Oriente Medio, el sur de Asia y -aunque en menor medidaEuropa y Norteamérica. Este trabajo pretende ofrecer una descripción de las características y del potencial de crecimiento de algunos esquemas de financiación compatibles con la Sharía, con el fin de preguntarnos si la práctica financiera islámica no encierra acaso algunos planteamientos éticos universales -o universalizables-, quién sabe si hasta una alternativa viable y humana a los esquemas de financiación convencionales que están en el origen mismo de la crisis económica.

Palabras claves: Instrumentos financieros, Sharía, financiación.

\section{FINANCIAL INSTRUMENTS COMPATIBLE WITH SHARIA: IS AN ALTERNATIVE TO CONVENTIONAL FINANCING ETHICS?}

\begin{abstract}
The demographic weight of the muslim population, along with the economic growth of some countries of the Persian Gulf has contributed

* Profesor de Derecho Mercantil, Universidad Pontificia Comillas ICAI-ICADE. Doctor en derecho por la Universität des Saarlandes. Correo electrónico: bruno.martin@der.upcomillas.es
\end{abstract}


to the current Islamic Financial Law representation of a legal practice increasingly implanted in countries from Africa, the Middle East, South Asia and to a lesser extent- Europe and North America. This paper aims to provide a description of the characteristics and potential growth of some financing schemes compatible with Sharia, in order to ask ourselves up to what extent the Islamic financial practice contains some universal ethical approaches, -or globalizable ones-, or even a feasible and human alternative to the conventional financial schemes that are part of the roots of the economic crisis

Key Words: Financial instruments, Sharia, financing

\section{INTRODUCCIÓN}

La industria financiera islámica, aún con poca presencia en España, ha experimentado un crecimiento notable en las últimas décadas, impulsada por la creciente acumulación de riqueza de los países islámicos exportadores de petróleo y por el fuerte aumento de la población musulmana, dentro y fuera del mundo islámico, que busca oportunidades y productos de inversión acordes con sus creencias religiosas. El derecho financiero islámico (denominado en inglés Islamic Finance o Shari'a Compliant Finance) es un cuerpo de normas mercantiles y, en particular, de contratación bancaria, coherente con los preceptos del Islam. En los últimos treinta años el derecho financiero islámico ha pasado de ser un estrecho nicho de mercado a representar una práctica jurídica cada vez más implantada en jurisdicciones de África, Oriente Medio y el sur de Asia y que encuentra cada vez mayor aceptación entre despachos de abogados, inversores y bancos internacionales.

El derecho financiero islámico ocupa a día de hoy un terreno híbrido en el que confluyen creencias religiosas basadas en la Sharía y consideraciones convencionales de rentabilidad financiera. Este mestizaje de intereses obedece a la preeminencia de la práctica bancaria convencional en todo el mundo islámico -incluso en aquellas jurisdicciones que más han adaptado su ordenamiento jurídico a la Sharía-y al carácter internacional de los sindicatos bancarios que promueven las grandes operaciones de financiación empresarial en países islámicos. Así, la incompatibilidad con la Sharía de algunos esquemas convencionales de financiación -como sucede, por ejemplo, con los sistemas remuneratorios basados en un tipo de interés o con la utilización de instrumentos derivados que entrañan un elemento de especulación-, exige que los operadores involucrados en esta 
práctica de mercado desarrollen nuevos esquemas que satisfagan tanto a los partícipes que precisan de una estructura de financiación compliant con los preceptos del Islam como a aquellos partícipes cuya principal preocupación reside en que el proyecto sea bankable en los mercados financieros internacionales ${ }^{1}$. Este trabajo examina los principales preceptos del Islam que pueden incidir en la configuración de la financiación empresarial así como los esquemas contractuales comúnmente utilizados para dar acomodo a las prioridades tanto de los partícipes que llamaremos islámicos como de aquellos otros partícipes que denominaremos convencionales. Se han considerado únicamente aquellas estructuras que se reputan compatibles con las principales escuelas de pensamiento suníes (madāhib) ${ }^{2}$ y con las directrices de los organismos supervisores de la ley y contabilidad islámica.

De acuerdo con el Fondo Monetario Internacional, en 2014 el superávit agregado por cuenta corriente de los países integrantes del Consejo de Cooperación del Golfo (CCG) ascendió a 310.000 millones USD, representativo del $15 \%$ del ahorro mundial ${ }^{3}$. Es llamativo que el ahorro generado en los países islámicos -especialmente en los estados del CCGrepresente a día de hoy una fuente aún poco aprovechada para alcanzar dos objetivos claves para la economía española como son la reactivación de la financiación externa y el incremento y diversificación geográfica de las exportaciones $^{4}$. En relación con el primer objetivo, la creación de estímulos que favorezcan la implantación de entidades financieras

1 La financiación de proyectos suele considerarse como uno de los sectores que mejor se adecuan a la ley islámica, dado su carácter participativo y porque el flujo de caja del proyecto con frecuencia es suficiente para pagar a los inversores, sin necesidad de instrumentos adicionales de deuda. De hecho, muchos proyectos de infraestructura en el CCG se han realizado con instrumentos de financiación islámicos, principalmente sukuk, ya sea con estructura subyacente de iyara, de istisna'a o como resultado de una combinación de ambas.

2 En la medida de lo posible, este trabajo trata de respetar las transcripciones del árabe al español propuestas en RILOBA, F., Gramática árabe-española, $3^{\mathrm{a}}$ ed., EDI-6, S.A.

3 Los países integrantes del CCG son Baréin, Kuwait, Omán, Catar, Arabia Saudí y los Emiratos Árabes Unidos. Datos agregados del Fondo Monetario Internacional para 2014: http://www.imf.org/external/ $\mathrm{pubs} / \mathrm{ft} / \mathrm{weo} / 2014 /$. A pesar de su preeminencia en el mercado de las finanzas islámicas, no incluimos en esta exposición a Irán -cuyo saldo por cuenta corriente asciende a 21.000 millones USD-, por las restricciones comerciales que pesan sobre el país y las consiguientes dificultades de negocio para entidades occidentales. A este respecto, véanse las recientes sanciones impuestas por la Reserva Federal de Estados Unidos a BNP Paribas: http://www.forbes.com/sites/francescoppola/2014/07/01/bnp-paribass-sanctions-penalty-is-not-enough/ 4 De acuerdo con las estimaciones del Fondo Monetario Internacional para el año 2014, los países con mayor superávit por cuenta corriente son Alemania (284.000 millones USD) y China (224.000 millones USD), seguidos a cierta distancia por Japón, Corea del Sur y Taiwán con aproximadamente 57.000 millones USD, respectivamente. En relación con el interés reciente del Gobierno de España en fomentar la inversión de empresas españolas en la región, sirva como ejemplo la visita del Rey a las monarquías del Golfo Pérsico en mayo de 2014: http://www.expansion.com/2014/05/18/economia/1400421999.html. Las empresas españolas de infraestructuras gozan de buena reputación en el mundo árabe. El grupo FCC se ha asegurado el desarrollo de parte del metro de Riad por 1,7 millardos de euros, lo que representa el encargo más grande de su historia. Otros consorcios españoles participan en el proyecto de desarrollar en Doha (Catar) una red de metro por valor de 100 millardos USD, así como un sistema de carreteras y las instalaciones del Mundial de Fútbol de 2022. Importes similares se manejan en Arabia Saudí con relación a la construcción de una red ferroviaria de alta velocidad en la que participa Talgo. 
islámicas exige una cierta adaptación del ordenamiento bancario español a las particularidades del derecho financiero islámico - especialmente en materia contable y fiscal- en línea con las recientes reformas iniciadas en el Reino Unido, Francia, Alemania y Luxemburgo ${ }^{5}$. En cuanto al segundo objetivo, la gran capacidad de inversión de los países del CCG unida a su política de desarrollo de infraestructuras y energías renovables, los convierte en un destino natural para la inversión española -baste indicar que siete de las diez mayores empresas de infraestructuras del mundo son españolas y que España es líder en tecnología termosolar, fotovoltáica y eólica-. Este trabajo parte de la base de que una mejor comprensión de las características y del potencial de crecimiento de algunos esquemas de financiación compatibles con la Sharía facilitará el acceso a la financiación islámica de la economía española así como las exportaciones en forma de proyectos de infraestructuras y energías renovables en países islámicos ${ }^{6}$.

\section{LA INDUSTRIA FINANCIERA ISLÁMICA}

\subsection{Antecedentes}

Aunque las finanzas islámicas son tan antiguas como el Islam, la industria financiera islámica moderna nace en Malasia en los años 50 del s. XX y empieza a generalizarse en Egipto a partir del año 1963 con la creación de la primera cooperativa de microcréditos denominada Mit $G h a m r^{7}$. En sus inicios, la actividad financiera islámica es muy básica

5 Si bien en los últimos años se ha podido constatar un interés creciente de ciertos fondos de inversión islámicos por la economía española. http://www.welt.de/print/die welt/wirtschaft/ article12770 2086/Spaniens-Sponsoren.html; http://www.expansion.com/2013/09/20/juridico/1379696815.html.

6 De acuerdo con los datos del Ministerio de Industria, Turismo y Comercio para 2014, los países islámicos representan el 4,2\% del PIB mundial y el $2 \%$ del destino de las exportaciones españolas. Véase a este respecto KESSLER RODRÍGUEZ, A., (2012), "Finanzas islámicas: Una oportunidad para España", Boletín Económico de ICE, $\mathrm{n}^{\circ} 3022$.

7 Los pioneros de la banca islámica son los egipcios Ahmad an-Naddyār (1932-1996) e 'Īsā'Abduh (†1980). An-Naddyār, que defendió su tesis doctoral en 1959 bajo la dirección de Heinrich Rittershausen en la Universidad de Colonia con una disertación sobre los obstáculos a las inversiones foráneas en Egipto ("Hindernisse direkter Auslandsinvestitionen in Ägypten"), era un buen conocedor del sistema de cajas de ahorro alemanas y emprendió en 1963 con el apoyo de Heinrich Rittershausen y de Günter Schmölders la creación de una caja de ahorros sin intereses en la localidad egipcia de Mit Ghamr, que captó en poco tiempo más de 200.000 depositantes de zonas rurales. En lugar de intereses los depositantes recibían el derecho a obtener créditos sin intereses y el apoyo de un fondo de donaciones religiosas para casos de extrema necesidad. Los depositantes de cuantías significativas participaban además en un fondo de inversión, que les aseguraba la participación en beneficios. El proyecto de Mit Ghamr fue finalizado por Nasser en 1967. El segundo pionero es 'İsā'Abduh, nacido en una familia cristiana egipcia, convertido al Islam antes de la Segunda Guerra Mundial y miembro de los Hermanos Musulmanes. Tras cursar estudios en la Universidad de Manchester publica varios libros en los que critica el sistema económico occidental y exhorta a la creación de entidades financieras compatibles con la Sharía. En los años 70 se convierte en asesor económico de los EAU. Desde este cargo colabora en la fundación del Dubai Islamic Bank en 1975.

Otros autores sostienen que el origen de la industria de la financiación islámica se remonta a finales del s. XIX con la apertura de la primera sucursal de Barclays en El Cairo, que fue fuertemente criticada debido al cobro de intereses. Véase GARCÍA HERRERO, A. / MORENO, C. / SOLÉ, J., "Finanzas Islámicas", Estabilidad Financiera, Banco de España, n 15, 121-141. 
debido en parte al subdesarrollo económico de la región, la utilización de modelos contractuales cerrados y arcaicos, la falta de expertos en la materia y la utilización exclusiva del árabe como lengua de contrato. La constitución en 1973 del Nasser Social Bank en Egipto representa la primera experiencia de banca comercial islámica a mayor escala. Entre los años 70 y 90 el derecho financiero islámico atraviesa profundos cambios relacionados con el desarrollo económico derivado de la exportación de petróleo en las monarquías del Golfo Pérsico, el Panislamismo y una nueva sensibilidad hacia el Islam. En este periodo surgen los primeros grandes bancos islámicos ${ }^{8}$, algunos -aunque pocosbancos occidentales crean un área de financiación islámica, las escuelas de pensamiento suníes realizan un esfuerzo por consensuar ciertas posiciones doctrinales (iyma) en materia financiera, se constituyen las primeras agencias de expertos islámicos (Sharia boards) ${ }^{9}$, los documentos contractuales empiezan a redactarse también en inglés, se abandonan progresivamente los modelos contractuales cerrados y se crean la AAOIFI y la IFSB. La aprobación en 1998 de la Dow Jones Islamic Indexes Fatwa supone un revulsivo para los mercados de capitales islámicos, dado que por primera vez se admite la noción de 'impureza tolerable' de ciertas operaciones financieras siempre que estén sujetas a mecanismos de 'depuración' consistentes en donaciones de escasa entidad para fines caritativos. Hasta los años 90, las principales áreas de práctica se centran en el sector inmobiliario y el capital riesgo. Con el tiempo la actividad financiera islámica deviene cada vez más compleja tanto desde el punto de vista contractual como de cuestiones evaluables bajo la Sharía. En los años 90 y principios de los 2000, los fondos de inversión acogidos a estructuras fiscales eficientes se convierten en el principal sector de negocio, especialmente los fondos de inversión inmobiliarios ${ }^{10}$. La emisión de letras del tesoro en forma de sukuk acordada en 2002 por el gobierno de Malasia representa otro gran hito en el desarrollo de las finanzas islámicas. A partir de 2004 algunos grandes bancos occidentales como Citibank, HSBC, RBS, UBS,

8 En 1975 se constituyen el Islamic Development Bank, que es el primer banco que se compromete a operar con arreglo a la Sharía, y el Dubai Islamic Bank, el primer banco islámico privado. En 1977 se fundan el Kuwait Finance House y el Faysal Islamic Bank,

9 En los primeros años son muy pocos los expertos en Sharía aplicable a la actividad financiera, por lo que son con frecuencia las mismas personas quienes forman parte de varios comités. Los más conocidos son los denominados Wall Street Sheijs que pertenecen, entre otros, al panel que asesora al índice islámico del Dow Jones.

10 En los años 90 destacan los fondos de inversión inmobiliaria, cuyo número aumenta significativamente tras el pinchazo de la Nueva economía. En un primer momento, estos fondos invierten principalmente en proyectos residenciales en Estados Unidos debido al boom inmobiliario y a los plazos cortos de construcción estadounidenses, pero también a que las restricciones de la Sharía no son aplicables a viviendas familiares y a que en Estados Unidos se empiezan a desarrollar estructuras de financiación compatibles con la Sharía (especialmente la istisna'a-iyara). 
Goldman Sachs o Deutsche Bank crean o amplían sus prácticas de Islamic Finance ${ }^{11}$, centradas principalmente en fondos de inversión, mercados de capitales y titulizaciones, si bien algunas operaciones son objeto de controversia por parte de los expertos islámicos. ${ }^{12}$

\subsection{La industria financiera islámica en cifras}

A pesar de su notable crecimiento en los últimos años, con la excepción de Irán, la industria financiera islámica sigue siendo minoritaria en los países islámicos, incluso en aquellos en los que el sistema financiero ha sido adaptado a la Sharía. En 2014 el valor total de los activos financieros islámicos en el mundo asciende aproximadamente a un billón USD, que representa apenas un 2\% de los activos financieros totales y su peso relativo es poco significativo fuera del CCG, Irán, Paquistán, Sudán y Malasia $^{13}$. En aquellos países islámicos en los que conviven banca islámica y banca convencional, suele predominar esta última de forma absoluta. En este sentido son llamativos los casos de Arabia Saudí y Malasia, donde el porcentaje de banca islámica no alcanza el 50\%, a pesar de disponer de un número elevado de entidades de crédito plenamente adaptadas a la Sharía ${ }^{14}$. No obstante, algunos observadores pronostican que en los próximos diez años entre el $40 \%$ y el $50 \%$ de los depósitos totales de ahorradores islámicos se realizaran en entidades de crédito islámicas. Según estos pronósticos, los principales mercados en los que se desarrollarán las finanzas islámicas serán China, India y Rusia ${ }^{15}$.

En cuanto al valor total de activos islámicos, el primer puesto lo ocupa Irán con 320 millardos USD, seguido a mucha distancia de Arabia Saudí y Malasia, con 140 y 105 millardos USD, respectivamente ${ }^{16}$. En 2014,

11 Destacan muy especialmente las prácticas islámicas de Citibank y HSBC Amanah.

12 Véase la controversia generada en el marco de la emisión de sukuk por Goldman Sachs en 2012: http://www.huffingtonpost.com/2012/02/23/refile-debate-rages-over- n 1296351.html.

13 En líneas generales, las entidades financieras islámicas han capeado la actual crisis económica en mejores condiciones que las entidades convencionales. Según algunos autores, esto es debido a que la Sharía prohíbe invertir, entre otros, en bonos de titulización hipotecaria, CDOs (collateralized debt obligations) y derivados. Los esquemas de riesgos e incentivos propios de las finanzas islámicas obligan a las entidades a una política de inversiones más prudente. Otros autores señalan que los factores que explican el buen comportamiento de las entidades financieras islámicas está relacionado con la ausencia de una gama diversificada de productos de inversión, la ausencia de una presión de mercado para la mejora de sus ratios de rendimiento y el incremento progresivo del precio de las materias primas energéticas.

14 Porcentaje de banca islámica sobre el total: Arabia Saudí (49,6\%), Malasia (18,3\%), EAU (16,7\%), Catar $(23,5 \%)$, Baréin (27,6\%), Kuwait (32,7\%), Egipto (3,7\%), Turquía (4,9\%), Indonesia (3,9\%), Paquistán (5,5\%). Elaboración propia a partir de E\&Y The World Islamic Banking Competitiveness Report 2010.

15 Véase E\&Y The World Islamic Banking Competitiveness Report 2010.

16 Activos islámicos totales en millardos USD: EAU (80), Kuwait (60), Baréin (45), Catar (40), Turquía (25), Reino Unido (19), Bangladesh (10), Sudán (10), Egipto (8), Indonesia (7), Paquistán (5), Siria (4), Jordania (3), Brunei (2), Yemen (1) y Tailandia (1). Elaboración propia a partir de E\&Y The World Islamic Banking Competitiveness Report 2010 
seis de los diez mayores bancos islámicos fueron iraníes. En conjunto, los bancos iraníes controlan además el $40 \%$ del total de activos islámicos de los cien primeros bancos islámicos del mundo ${ }^{17}$. La principal plaza financiera es Kuala Lumpur, seguida de Baréin, Dubái y Kuwait. Londres destaca como principal plaza financiera fuera del mundo islámico. Desde el año 2006 el gobierno de Singapur ha adoptado algunas medidas de estímulo para introducirse en este mercado.

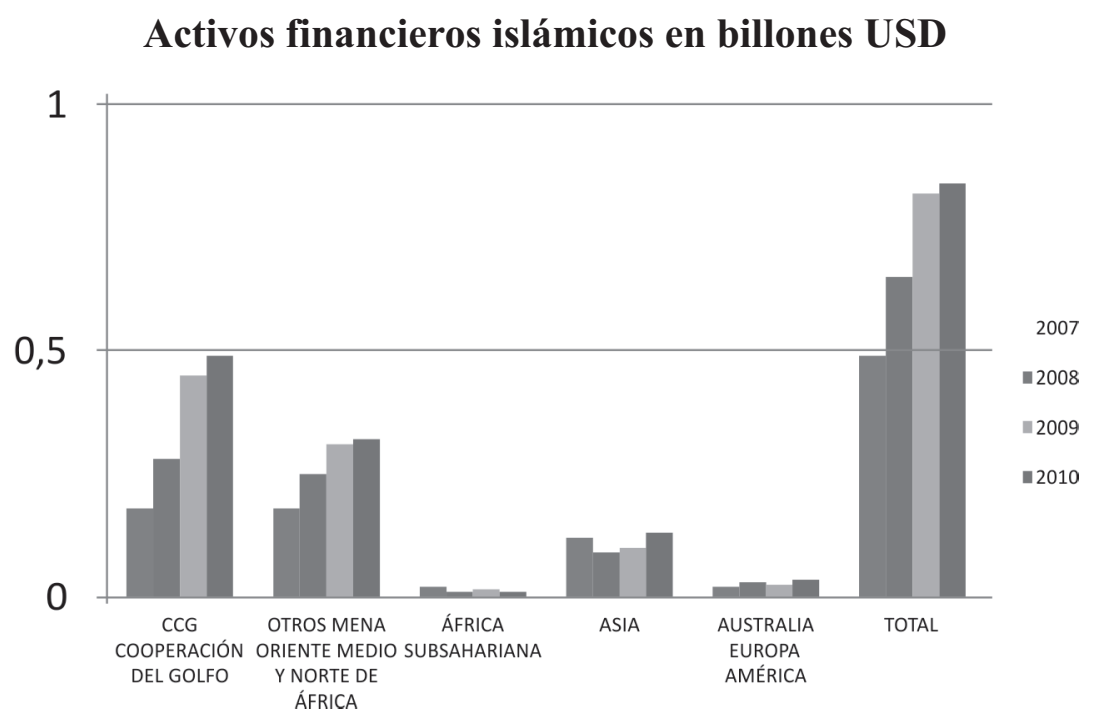

Fuente: Elaboración propia a partir de datos de The Banker 2010.

\section{LA INDUSTRIA FINANCIERA ISLÁMICAEN OCCIDENTE}

La importancia que las finanzas islámicas están adquiriendo en Estados Unidos y la Unión Europea desde el inicio de la crisis está relacionada con la necesidad creciente de crédito en amplios sectores de la economía $^{18}$. En Estados Unidos se han constituido varias entidades de crédito plenamente adaptadas a la Sharía, que ofrecen hipotecas, depósitos y fondos de inversión islámicos y que están especialmente presentes en el mercado inmobiliario residencial. También existen los índices bursátiles Islamic Dow Jones y Times Stock Exchange Global Islamic Index Series y desde el año 2006 se han visto algunas emisiones

17 Los bancos más destacados son Bank Melli Iran (Irán), Al Rajhi Bank (Arabia Saudí), Bank Mellat y Bank Saderat (ambos de Irán). El banco más importante en el Sudeste Asiático es el Islami Bank Bangladesh Ltd. Véase a este respecto ANCA, C. DE, (2014), "Finanzas islámicas: ¿Cuál es el interés para Europa?”, Observatorio de Divulgación Financiera, $\mathrm{n}^{\circ} 14$.

18 Acerca de las finanzas islámicas en otros países como Canadá y Australia, véase ASHRAF, U.K. I ABDEL, K.H., (2006) "The influence of Quran and Islamic financial transactions and banking", Arab Law Quarterly, vol. 20, n³, p. 327. 
de sukuk por sociedades cotizadas estadounidenses ${ }^{19}$. En el Reino Unido es especialmente destacable el esfuerzo de las autoridades regulatorias de crear un marco legal favorable a las financiaciones islámicas. En el año 2000 el Banco de Inglaterra crea un grupo de trabajo sobre finanzas islámicas bajo la presidencia de Lord Edward George, que conduce a la eliminación del impuesto sobre actos jurídicos documentados (stamp duty tax) en los casos de doble imposición de ciertas operaciones inmobiliarias ${ }^{20}$. En 2004 el órgano de supervisión financiera del Reino Unido (Financial Services Authority, FSA) autoriza el primer banco europeo que opera exclusivamente con arreglo a la Sharía, el denominado Islamic Bank of Britain plc ${ }^{21}$. Aunque finalmente no se lleva a cabo, es significativo que en 2008 el gobierno del Reino Unido anuncie una posible emisión de deuda pública representada en sukuk. En 2013 el gobierno del Reino Unido constituye un grupo de trabajo denominado Islamic Finance Task Force (IFTF), con el fin de promocionar a la City de Londres como principal centro financiero islámico fuera del mundo musulmán ${ }^{22}$. Gracias a las medidas legales y fiscales adoptadas a lo largo de la última década, en la actualidad el Reino Unido lidera la industria financiera islámica en Occidente con 19.000 millones USD en activos islámicos y 22 bancos adaptados a la Sharía, cinco de los cuales son enteramente islámicos ${ }^{23}$. En Europa continental, Luxemburgo es el país

19 En Estados Unidos destaca la financiación islámica en el sector de las hipotecas inmobiliarias, estimulada especialmente por la Federal National Mortgage Association (Fannie Mae) y la Federal Home Mortgage Corporation (Freddie Mac) como consecuencia de dos documentos interpretativos de 1997 y 1999 aprobados por la Office of the Comptroller of the Currency, que autorizan la contratación de créditos hipotecarios islámicos sobre la base de iyara y mubaraha, respectivamente. En materia de capital investment, destaca Arcapita Bank, con sede en Baréin y gran implantación en Estados Unidos. También es destacable el proyecto Los Angeles Reliable Investment Bankers Associates (LARIBA) de la American Finance House y la Amana Mutual Funds Trust. Véase CANALEJO LASARTE, G. / CABELLOS BALLENILLA, A., (2009), “Apuntes sobre los contratos «islámicos» de financiación desde la perspectiva del derecho español”, Actualidad Jurídica Uría Menéndez, n²23, p. 24

20 Véase: https://www.gov.uk/government/uploads/system/uploads/attachment data/file/253141/UKTI U

$\mathrm{K}$ Excellence in Islamic Finance.pdf.

21 Véase: http://www.islamic-bank.com/.

22 Son ilustrativas las palabras de Gordon Brown que ya en 2006 quería convertir al Reino Unido en capital de la financiación islámica mundial: "Making the UK and London a centre for Islamic finance means putting in place the tax and legislative framework that is supportive of Islamic products. On top of this, we're also looking at promoting the City abroad as a centre for Islamic finance". Véase el artículo publicado en Financial Times: http://www.ft.com/intl/cms/s/0/00a235ba-015d-11db-af16-0000779e23 40.html\#axzz32qFuauYP.

23 Sin embargo, no todo han sido facilidades en el Reino Unido. Véanse a este respecto las sentencias Symphony Gems y Beximco, en las que los tribunales ingleses deniegan la validez de la cláusula estándar de sumisión de contrato a la Sharía que reza: "Subject to the Principles of the Glorious Shari'a this Agreement shall be governed by and construed in accordance with the laws of England". Los tribunales argumentan que la Sharía no constituye ley de una determinada jurisdicción a los efectos del Reglamento de Roma I y que un contrato no puede estar sometido a dos ordenamientos. Véase England and Wales Court of Appeals (Civil Division), de 28 de enero de 2004 en el caso Shamil Bank of Bahraim EC vs. Beximco Pharmaceuticals LPD \& others; Commercial Court, 14 de diciembre de 2007, Islamic Investment Company of the Gulf (Bahamas) Ltd. vs. Symphony Gems NV and others. Véase comentario de las dos sentencias en CHUAH, J.C.T., (2006), "Islamic Principles Governing International Trade Financing Instruments: A Study of the Morabaha in English Law", Northwestern Journal of International Law and Business, vol. 27, n 1 Fall, p. 137-170. 
pionero con la primera emisión de sukuk en un mercado bursátil en $2002^{24}$. Otros países como Francia ${ }^{25}$, Alemania ${ }^{26}$ y Suiza ${ }^{27}$ han emprendido algunas reformas con el fin de dar acomodo legal a las estructuras de financiación islámicas ${ }^{28}$. En España, el paso más significativo hacia la introducción de las financiaciones islámicas en nuestro ordenamiento jurídico es la creación en 2009 del Centro Islámico de Economía y Finanzas en Europa y del Saudi-Spanish Center for Islamic Economics ${ }^{29}$.

\subsection{El derecho islámico}

El derecho islámico describe el conjunto de normas seculares inspiradas o compatibles con la Sharía. En su acepción actual, la Sharía representa el cuerpo de normas que obliga al musulmán en todos los aspectos de la vida $^{30}$. La Sharía comprende normas religiosas, morales, éticas y estrictamente jurídicas. La Sharía es en parte revelación divina, ejemplos de vida del profeta Mahoma y raciocinio teológico. Desde un punto de vista formal, el derecho divino emanado de la Sharía aparece recogido en el Corán y en la Sunna. El Corán es el libro sagrado del Islam y su texto -al decir de los creyentes- es idéntico a la revelación transmitida al profeta Mahoma por el arcángel Gabriel ${ }^{31}$. La Sunna designa el modo musulmán de conducir las interacciones políticas, sociales y económicas $^{32}$. La Sunna se rige por los hadices, esto es, las narraciones

24 En relación con la implantación de la financiación islámica en Europa continental, véase "La finance islamique: l'ouverture européenne", Revue banque, nº 696, 2007, citado en CANALEJO LASARTE, G. / CABELLOS BALLENILLA, A., (2009), “Apuntes sobre los contratos «islámicos» de financiación desde la perspectiva del derecho español”, Actualidad Jurídica Uría Menéndez, nº23, p. 21-44.

25 Véase la comisión creada por iniciativa de Christine Lagarde durante su mandato como Ministra de Economía, Finanzas e Industria, con el objetivo de permitir el desarrollo de ciertos productos islámicos (murabaha, sukuk e iyara) y de posicionar a París como capital financiera islámica en competencia con Londres. 26 En Alemania ha sido pionero el Land de Baja Sajonia con su emisión de sukuk por importe de 100 millones de euros en 2004

27 UBS liquida a finales de 2006 a Noriba, su filial islámica creada en 2002 en Manama.

28 Francia y Luxemburgo llevan barajando la creación de bancos islámicos desde 2008: http://www.alkanz.org/2013/07/02/france-finance-islamique-cedef/.

29 http://www.ie.edu/es/ie-foundation/investigacion-aplicada/centros/centro-de-economia-y-finanzasislamicas y http://www.scief.es/news_fut.php.

30 En su acepción inicial, el término 'Sharía' aludía al camino que lleva a los camellos al agua. En un sentido alegórico, describe el medio que lleva al sustento esencial de la vida. También se suele traducir como 'el camino a la paz' o 'el mejor camino a seguir'.

31 Si bien el Corán es la revelación final e inmutable de Alá, no equivale a un código de leyes en sentido jurídico. Los versículos directamente relacionados con el derecho son apenas 200 y aquellos que tratan cuestiones financieras son escasísimas. La primera compilación escrita del Corán data de tiempos del tercer califa, Osmán ibn Afan (650 y 656 d.C.).

32 Acerca de la evolución del término 'Sunna' como elemento de fiqh véase ANSARI, Z.I., (2004), "Islamic juristic terminology before Shafi: A semantic analysis with special reference to the Kufa", en HALLAQ, W.B., The Formation of Islamic Law. El autor señala que aunque el Corán contiene dieciséis referencias al término 'sunna', ninguna de ellas se refiere específicamente a la sunna del mensajero de Alá. No obstante, el Corán es claro a la hora de establecer que el ejemplo del profeta Mahoma representa la forma más elevada de vida humana. 
escritas de palabras, mensajes y actitudes atribuidos al profeta Mahoma, tal y como fueron transmitidos por sus discípulos o descendientes directos $(\text { sahaba })^{33}$.

La interpretación de la Sharía se denomina $f i q h^{34}$. El conocimiento de la Sharía opera a través del método deductivo que busca la aplicación del principio general a la situación concreta y recibe la denominación de iytihad. La iytihad adopta varias formas ${ }^{35}$ : qiya, que es una interpretación analógica que pretende comparar dos situaciones con arreglo al Corán, la Sunna y la iyma; istihsan, que describe las preferencias de un individuo o corriente de pensamiento; istihlal, que describe la heterodoxia; y 'urf, costumbre. La iyma describe el consenso con fuerza de ley de un grupo de muytahid especialmente habilitados para practicar la iytihad. Otras técnicas importantes son la takhayyur -la identificación de soluciones entre las diferentes escuelas de pensamiento- y la talfiq -fusión de diferentes opiniones legales- con el fin de dar cumplimiento a la maslaha-en sentido amplio, interés general- ${ }^{36}$.

Los principios de la Sharía son ambiguos debido a los diferentes métodos exegéticos del Corán (tafasir) y a la práctica de iytihad ${ }^{37}$. Esto implica que en ocasiones se den opiniones ( fatawa) divergentes sobre un mismo aspecto de la Sharía. La aplicación de diferentes métodos exegéticos ha terminado cristalizando en múltiples escuelas de pensamiento $\left(\right.$ madāhib) ${ }^{38}$, enmarcadas dentro de las tradiciones chií y suní. Por su importancia para el tráfico económico y, en particular, por su influencia sobre el derecho financiero islámico, interesa mencionar aquí las cuatro grandes escuelas ortodoxas suníes, la 'Hanafí', 'Shafí', 'Malikí'

33 La validez de un hadiz pasa por el reconocimiento de la cadena de vínculos hasta el profeta Mahoma o su entorno directo. En tiempos del tercer califa los hadices fueron sometidos a un proceso de verificación realizado por los jurisconsultos o muytahids. Desde entonces la clasificación más importante distingue entre hadices maqbul (aceptados) y mardud (rechazados). Los hadices aceptados pueden ser sahih (verdaderos) o hasan (aceptables). Estrechamente relacionados con los hadices están los atar, las palabras, mensajes y actitudes de los discípulos del profeta Mahoma o sus descendientes directos, que sirven para interpretar los hadices. Las tradiciones islámicas suní, chií e ibadí aceptan casi unánimemente las recopilaciones de hadices de Al-Bujari que recoge 7.275 hadices extraídos de 600.000 posibles y de Muslim ibn al-Haŷŷaŷ (f. 875), que recoge 9.200 extraídos de 300.000 posibles. También gozan de amplia aceptación las recopilaciones de Abu Da'ud (f. 888), Al-Tirmidhi (f. 892), Al-Nasa'i (f. 915) y Ibn Maŷa (f. 886).

34 Literalmente 'conocimiento', derivado de faqaha (conocer).

35 Literalmente 'esfuerzo', generalmente traducido como 'razonamiento jurídico'.

36 Véase KRAWIETZ, B., (2002), Cut and Paste in Legal Rules: Designing Islamic Norms with Talfiq, Welt des Islams, p. 3.

37 A propósito de la aplicación de iytihad en el derecho financiero islámico, véase AL-AWANI, T.J. / ELENSARY, W., (1999), Linking Ethics and Economics: The Role of Ijtihad in the Regulation and Correction of Capital Markets, Proceedings of the Second Harvard University Forum on Islamic Finance: Islamic Finance into the 21 st Century, Harvard University

38 Siguiendo a Ferdinand de Saussure diríamos que el Islam, como otros sistemas de fe, establece una langue unitaria representada por la Sharía, en tanto que su parole ofrece un espectro amplio de creencias y rituales -pensemos tan solo en las líneas divisorias entre suníes y chí́es o entre el sufismo y el Islam popular-. 
y 'Hanablí' ${ }^{39}$. Tradicionalmente, cada escuela interpreta y aplica la Sharía de forma distinta a los mismos hechos. La disciplina que estudia las diferencias interpretativas entre las escuelas se denomina khilaf.

Aunque la Sharía no constituye un código de leyes como tal, contiene algunos preceptos aplicables a las relaciones jurídico-privadas como son la compraventa (bay'), arrendamiento (iyara), cesión de obligaciones (hawala), hipoteca y prenda (rahn), depósito (emanet), préstamo, regalo (hiba), comunidad de bienes (sarikat, musaraka y mudaraba) e insolvencia (taflis). Cada una de las instituciones anteriores ha sido objeto de amplia interpretación por las escuelas de pensamiento islámicas.

El grado de reconocimiento de la Sharía como fuente del derecho en los ordenamientos jurídicos seculares oscila entre la falta total de reconocimiento -Estados Unidos, los Estados miembros de la UE, Japón, Corea o China- y la designación como principal fuente del derecho- los países del CCG, Mauritania, Sudán, Irán, Iraq, Afganistán, Pakistán, Brunei o, en menor medida, Malasia e Indonesia- ${ }^{40}$. También se encuentran diferencias notables en la aplicación de la Sharía en aquellas jurisdicciones que han optado por adaptar sus ordenamientos jurídicos al Islam. Aunque las finanzas islámicas han estado dominadas tradicionalmente por las monarquías del CCG, en la actualidad destaca Malasia como jurisdicción más innovadora y flexible en la materia.

\subsection{Principios básicos del derecho financiero islámico}

Algunos autores definen la 'economía islámica' como una economía de mercado sujeta a los principios morales del Islam $^{41}$. El derecho

39 Las cuatro escuelas suníes son la 'Hanafí', fundada por el imán Abu Hanifa Numan Ibn Thabit, que representa la principal escuela de los musulmanes suníes, predomina en el sur y centro de Asia y está basada principalmente en la deducción lógica; la 'Shafí', fundada por el imán Ash-Shafi, que es la segunda escuela más difundida y predomina en los países musulmanes del Sudeste Asiático y propugna una aplicación rigurosa de los principios legales y excluye la aplicación del juicio individual ante la existencia de norma; la 'Malikí', fundada por el imán Malik Ibn Anas, que predomina en el Magreb y, además del Corán y la Sunna, admite el consenso de los doctores de Medina; y la 'Hanablí', fundada por el imán Ahmed Ibn Hanbal, que está fundada en una interpretación rigorista de la ley islámica y que predomina en la península arábiga. Véase SCHACHT, J., The Schools of Law and later developments in jurisprudence, en KHADDURI, M. I LIEBESNY, H.J., Law in the Middle East, p. 57-84.

40 La Sharía como ordenamiento aplicable a las operaciones comerciales desaparece casi totalmente con la colonización de los países de Oriente Medio por las potencias europeas a lo largo del s. XIX. Los hitos más destacables en este proceso de occidentalización son la conquista de Egipto por Napoleón en 1798 y la celebración del tratado Balta-Liman entre el Reino Unido y el Imperio Otomano en 1838. Como señala Hourani "the Shari'a was abandoned with astonishing speed and completeness", véase HOURANI, A., (1983)Arabic thought in the liberal age 1798-1939, Cambridge, p. 350.

41 Esta afirmación puede ser válida para describir los sistemas económicos de la mayoría de países islámicos en la actualidad. No obstante, especialmente en el periodo del Panislamismo, el término 'economía islámica' estaba fuertemente inspirado por el modelo de economía planificada de los países socialistas. 
financiero islámico sería un cuerpo de normas jurídico-privadas y, en particular, de contratación bancaria, coherente con los preceptos de la Sharía ${ }^{42}$. Como es también habitual en los ordenamientos privados occidentales, en el derecho islámico rige el principio de autonomía privada de la voluntad, esto es, se presume que está permitido (halal) todo lo que no está expresamente prohibido (haram). De acuerdo con las cuatro grandes escuelas de pensamiento suníes, el derecho financiero islámico está basado sobre cinco principios, tres negativos y dos positivos. De acuerdo con la clasificación comúnmente aceptada, los tres principios negativos son la prohibición de riba (exceso o incremento), prohibición de garar y maysir (incertidumbre y especulación) y prohibición de invertir en determinados productos o actividades haram. Los dos principios positivos establecen la obligación de repartir pérdidas y ganancias entre las partes contractuales y la obligación de que todo negocio guarde relación con un activo subyacente tangible ${ }^{43}$.

La prohibición de riba está expresamente mencionada en varios pasajes del Corán y de la Sunna. La prohibición de riba constituye la clave de bóveda del derecho financiero islámico y es quizá el rasgo que más lo diferencia del derecho financiero convencional. En su acepción más amplia el término riba describe el valor añadido obtenido por una parte contractual sin contraprestación. En sentido estricto, comprende el exceso o incremento sobre el importe de un principal cifrado en dinero que se devenga por el mero transcurso del tiempo ${ }^{44}$. De acuerdo con esta concepción y a diferencia de la financiación convencional en la que el prestamista obtiene un derecho al interés que es independiente de los resultados prósperos o adversos de la actividad financiada, el prestamista debe asumir el riesgo y ventura -las pérdidas y gananciasdel negocio en el que invierte sus fondos ${ }^{45}$. Es importante señalar que para el derecho financiero islámico no existe una diferencia entre el

42 El término 'derecho financiero islámico' no está ausente de controversia. La mayoría de los autores convienen, sin embargo, que existen modalidades contractuales suficientemente perfiladas que permiten hablar de un 'derecho financiero islámico' y no solo de una concepción islámica de la financiación.

43 Véase a este respecto, LARAMÉE, J.P. (coord.), (2008), La finance islamique a la française, un moteur pour l'économie, une alternative éthique, Secure Finance, p. 91.

44 Existen dos acepciones de riba: (i) riba al-nasiyah, que describe el incremento recibido por un prestamista sobre el principal prestado y que es comparable al 'interés' en una financiación convencional; y (ii) riba al$\mathrm{fadl}$, que describe el exceso que entrega una parte contractual y por la que no recibe contraprestación.

45 La bibliografía sobre el concepto riba es muy extensa. Por citar únicamente las obras más representativas, véase FADL, M.H., "Riba, Efficiency and Prudential Regulation, a presentation at the symposium Islamic Law in a Globalized World: Implications for Contemporary Islamic Finance, University of Wisconsin, March 2, 2007", Twenty-Fifth Anniversary of the University of Wisconsin International Law Journal, 2007 así como la opinión legal de Muhammed Taqi Usmani en The Text of the Historic Judgment on Riba Given by the Supreme Court of Pakistan, 23 de diciembre de 1999, accessible bajo http://www.albalagh.net/ Islamic_economics/riba_judgement.shtml 
préstamo usurario y el préstamo con interés. Ambos préstamos se encuentran en el ámbito de aplicación de la prohibición, siendo el primero simplemente un préstamo con un interés más elevado. Si bien la riba no está necesariamente vinculada al dinero como activo subyacente, conviene destacar además que el dinero carece de valor intrínseco y cualesquiera ganancias generadas sobre el dinero están prohibidas por la Sharía ${ }^{46}$.

Las prohibiciones de garar y de maysir están estrechamente vinculadas y se refieren a la incertidumbre y a la especulación, respectivamente. Los presupuestos objetivos de la prohibición de garar exigen que la incertidumbre tenga cierta relevancia o entidad, no bastando la incertidumbre sobre aspectos nimios o desdeñables; que se dé en negocios que conlleven prestaciones recíprocas; y que recaiga sobre un elemento esencial del negocio. De acuerdo con este principio, no son admisibles por ejemplo el seguro convencional y las opciones de compra y venta con beneficio desconocido. No obstante, la incertidumbre no debe confundirse con el riesgo de negocio, que sí es compatible con la Sharía $^{47}$. La prohibición de maysir se ciñe a la obtención de beneficios mediante la suerte o especulación. De acuerdo con este precepto, los contratos de derivados que entrañan un fin especulativo son incompatibles con la Sharía. En la práctica, la distinción entre especulación ilícita y riesgo empresarial legítimo puede ser difícil de trazar, especialmente en los casos de toma de participación en una sociedad con vistas a obtener un retorno en forma de dividendos.

La prohibición de invertir en productos o actividades haram se refiere tradicionalmente a los juegos de azar, pornografía, carne de cerdo, alcohol $^{48} \mathrm{y}$, según algunos expertos islámicos, el tabaco, las armas de fuego, el cine y la música. En los últimos años es cada vez más frecuente que los expertos islámicos se pronuncien en contra de la inversión en actividades de seguros, de financiación convencional basada en tipos de interés y de intermediación financiera. La prohibición de invertir en

46 Acerca del origen histórico de la riba, véase CANALEJO LASARTE, G. / CABELLOS BALLENILLA, A., (2009), Apuntes sobre los contratos «islámicos» de financiación desde la perspectiva del derecho español, Actualidad Jurídica Uría Menéndez, n² 23, 2009, nota al pie 28.

47 Conviene señalar que la Sharía no se opone a la obtención de beneficios o ganancias en general -recordemos que el profeta Mahoma se dedicaba al comercio-. No obstante, la línea que separa la incertidumbre entendida como 'riesgo del comerciante', que está plenamente aceptada por la Sharía, de la 'incertidumbre' entendida como garar es sinuosa. Los expertos islámicos coinciden en distinguir estos conceptos atendiendo a si el resultado de un determinado negocio es susceptible de medirse en términos probabilísticos. Siempre que los modelos financieros otorguen un cierto carácter de predictibilidad a un negocio podremos hablar de 'riesgo de comerciante' compatible con la Sharía.

48 La prohibición de invertir en actividades relacionadas con la carne de cerdo y el alcohol para consumo humano suele comprender a productores, distribuidores e incluso a supermercados, restaurantes y hoteles. 
productos o actividades haram se extiende asimismo a la inversión en inmuebles en los que pueda tener lugar el comercio sobre los mismos. En la práctica, dado el grado de diversificación e interconexión de las actividades empresariales, puede llegar a ser extraordinariamente difícil determinar en qué medida una empresa está involucrada o no en actividades haram. Los expertos islámicos han desarrollado técnicas de 'tolerancia' y 'depuración' de la inversión en productos y actividades haram basadas en el cumplimiento de ciertos requisitos, como por ejemplo que el negocio principal que es objeto de la inversión sea halal; que los beneficios obtenidos de actividades prohibidas representen un porcentaje comparativamente menor respecto del beneficio total obtenido -habitualmente entre el $5 \%$ y el $20 \%$, dependiendo del criterio del experto islámico en cuestión-; que el importe total de la deuda sujeta al pago de intereses no exceda un determinado porcentaje del valor de los activos o capitalización bursátil de la sociedad -habitualmente entre el $25 \%$ y el $35 \%$-; o que el importe total de créditos a cobrar sujeto al pago de intereses no exceda un determinado porcentaje del valor de los activos o capitalización bursátil de la sociedad -habitualmente entre el $25 \%$ y el $33 \%{ }^{-}{ }^{49}$.

\section{CONCLUSIONES}

La industria financiera islámica ha experimentado un crecimiento notable durante las últimas décadas, impulsada por la creciente acumulación de riqueza de los países islámicos exportadores de petróleo y por el fuerte aumento en la población musulmana en el mundo. El derecho financiero islámico es un cuerpo de normas de contratación bancaria coherente con los preceptos del Islam. El derecho financiero islámico ha pasado de ser un estrecho nicho de mercado a representar una práctica jurídica firmemente establecida en países de África, Oriente Medio y el sur de Asia, que encuentra cada vez mayor aceptación entre despachos de abogados, inversores y bancos internacionales.

De acuerdo con las cuatro grandes escuelas de pensamiento suníes, el derecho financiero islámico está basado sobre cinco principios, tres negativos y dos positivos. De acuerdo con la clasificación comúnmente aceptada, los tres principios negativos son la prohibición de riba (exceso $\mathrm{o}$ incremento), prohibición de garar y maysir (incertidumbre $\mathrm{y}$ especulación) y prohibición de invertir en determinados productos o actividades haram. Los dos principios positivos establecen la obligación

49 Acerca de las técnicas de depuración, véase ALASRAG, H., "Principals of the Islamic Finance: A focus on Project Finance", disponible en SSRN 1806305, p. 18. 
de repartir pérdidas y ganancias entre las partes contractuales y la obligación de que todo negocio guarde relación con un activo subyacente tangible. Las dos técnicas que mejor responden a esta concepción de la financiación son la mudaraba y musaraka, asimilables (no idénticas) a un contrato de cuenta en participación y a un contrato de joint venture, respectivamente. Dado que la asunción de todo o parte del riesgo empresarial por parte de los acreedores encaja mal con los esquemas de financiación convencionales, algunas técnicas de financiación islámica han tenido que ser adaptadas a los estándares internacionales, pero sin perder su compatibilidad con la Sharía. Entre los esquemas contractuales adaptados destacan la murabaha (comisión de compra y compraventa con pago diferido), istisna'a (contrato de obra) e iyara (arrendamiento). La forma de emisión de deuda mejor adaptada es el sukuk, que funciona de forma similar a un bono de titulización.

El ahorro generado en los países islámicos -especialmente en los estados del CCG-representa a día de hoy una fuente aún poco aprovechada para la financiación y exportación de las empresas españolas. Resulta llamativo que el legislador español no haya iniciado aún las adaptaciones oportunas del ordenamiento bancario español a las particularidades de la ley islámica - especialmente en materia contable y fiscal- con el fin de facilitar la implantación de entidades financieras islámicas en España, en línea con las recientes reformas iniciadas en el Reino Unido, Francia, Alemania y Luxemburgo. Dicho esto y a la vista de las experiencias comparadas, es evidente que la incorporación al ordenamiento jurídico español de instrumentos financieros conformes con la Sharía presenta notables retos jurídicos, entre ellos el tratamiento 'fiscalmente eficiente' de ciertas figuras contractuales así como los costes de transacción derivados de su escasa delimitación conceptual, la inseguridad jurídica derivada de una práctica bancaria basada en escuelas de pensamiento divergentes y la cuestionable validez de las cláusulas de sumisión contractual a la Sharía.

Por último, al margen de la pura oportunidad económica de una reforma legislativa en los términos anteriores, cabe preguntarnos si la práctica financiera islámica no encierra acaso algunos planteamientos éticos universales -o universalizables-, quién sabe si hasta una alternativa viable y humana a los esquemas de financiación convencionales que están en el origen mismo de la crisis económica ${ }^{50}$.

50 La Santa Sede se ha pronunciado sobre la bondad de las finanzas islámicas en un conocido editorial del Osservatore Romano de marzo de 2009: http://archiviostorico.corriere.it/2009/marzo/04/ Osservatore_impari_dalla_finanza_islamica_co_8_090304012.shtml. 


\section{REFERENCIAS BIBLIOGRÁFICAS}

AL-AWANI, T.J. / EL-ENSARY, W., "Linking Ethics and Economics: The Role of Ijtihad in the Regulation and Correction of Capital Markets", Proceedings of the Second Harvard University Forum on Islamic Finance: Islamic Finance into the 21st Century, Cambridge, Massachusetts, Center for Middle Eastern Studies, Harvard University, 1999, p. 99-126.

AL-ZAHAYLI, W., (2003), Financial Transactions in Islamic Jurisprudence, Dar Al-Fikr.

ALASRAG, H., Principals of the Islamic Finance: A focus on Project Finance, disponible en SSRN 1806305.

ANCA, C. DE, (2014), Finanzas islámicas: ¿Cuál es el interés para Europa?, Observatorio de Divulgación Financiera, $\mathrm{n}^{\mathrm{o}} 14$.

ANSARI, Z.I., (2004) Islamic juristic terminology before Shaf'i: A semantic analysis with special reference to the Kufa, en HALLAQ, W.B., The Formation of Islamic Law.

ASHRAF, U.K./ABDEL, K.H.,(2006) The influence of Quran and Islamic financial transactions and banking, Arab Law Quarterly, vol. 20, nº 3, p. 321-331.

CANALEJO LASARTE, G. / CABELLOS BALLENILLA, A., (2009), Apuntes sobre los contratos «islámicos» de financiación desde la perspectiva del derecho español, Actualidad Jurídica Uría Menéndez, $\mathrm{n}^{\circ}$ 23, p. 21-44.

CHUAH, J.C.T., (2006) Islamic Principles Governing International Trade Financing Instruments: A Study of the Morabaha in English Law, Northwestern Journal of International Law and Business, vol. 27, $\mathrm{n}^{\mathrm{o}} 1$ Fall, p. 137-170.

DEWAR, J. / HUSSAIN, M.M., (2011), Islamic Project Finance en DEWAR, J. (coord.), International Project Finance. Law and Practice, New York

EL GAMAL, M.A., (2008), Interest' and the Paradox of Contemporary Islamic Law and Finance, Fordham International Law Journal, $\mathrm{n}^{\mathrm{o}} 108$, 2003, p.108-149. 
---(2008) Islamic Finance: Law, Economics and Practice, Cambridge.

FADL, M.H., (2007), Riba, Efficiency and Prudential Regulation, a presentation at the symposium Islamic Law in a Globalized World: Implications for Contemporary Islamic Finance, University of Wisconsin, March 2, 2007, Twenty-Fifth Anniversary of the University of Wisconsin International Law Journal

FOSTER, N.H.D., (2007), Islamic Finance as an emergent legal system, Arab Law Quarterly, vol. 21, n² 2, p.170-188.

GArcíA HERrero, A. / MORENO, C. / SOLÉ, J., Finanzas Islámicas, Estabilidad Financiera, Banco de España, nº 15, p. 121-141.

HEGAZY, W., (2005), Fatwas and the Fate of Islamic Finance: A Critique of the Practice of Fatwa in Contemporary Islamic Financial Markets, en ALI, Islamic Finance, Current Legal and Regulatory Issues, p. 132-146.

HOURANI, A., (1983), Arabic thought in the liberal age 1798-1939, Cambridge.

KESSLER RODRÍGUEZ, A., (2012), Finanzas islámicas: Una oportunidad para España, Boletín Económico de ICE, $\mathrm{n}^{\circ} 3022$.

KHNIFER, M., (2010), Maslahah and the Permissibility of Organized Tawarruq, Opalesque Islamic Finance Intelligence, no. 8.

KRAWIETZ, B., (2002), Cut and Paste in Legal Rules: Designing Islamic Norms with Talfiq, Welt des Islams, p. 3-40.

LARAMÉE, J.P. (coord.), (2008), La finance islamique a la française, un moteur pour l'économie, una alternative éthique, Secure Finance.

LEE, K.H. / SON, S.H., (2013), Trends of Islamic Project Finance: A study on the GCC Region, World Economy Update, vol. 3, $\mathrm{n}^{\circ} 24$.

MCMILLEN, M.J.T., Shari'ah-compliant Project Finance: A structural overview, disponible en SSRN 1753252.

-Trends in Islamic Project and Infrastructure Finance in the Middle East: Re-Emergence of the Murabaha, disponible en SSRN 1753252. 
PARK, T.J., Recession in the Global Project Finance Market, Capital Market Weekly, 2012-18, Korea Capital Market Institute.

POWER, C., (2009), Faith in the market, Foreign Policy, n ${ }^{\mathrm{o}} 170$, enerofebrero p. 70-75.

RILOBA, F., Gramática árabe-española, $3^{\mathrm{a}}$ ed., EDI-6, S.A.

SCHACHT, J., The Schools of Law and later developments in jurisprudence, en KHADDURI, M. / LIEBESNY, H.J., Law in the Middle East, p. 57-84.

SHAIKH MS, S.A., Corporate Finance in an interest free economy: An alternate approach to practiced Islamic Corporate Finance, disponible en SSRN 1527310. 